\title{
Assessment of Oxide Descaler Functionality in a Steel Hot Rolling Mill Using Infrared Video Imaging
}

\author{
J. B. Wiskel, A. Linchieh and H. Henein
}

\author{
Dept. of Chemical/Materials Engineering, University of Alberta, Edmonton, Alberta, Canada. T6G 2V4
}

\begin{abstract}
A series of infrared temperature videos were taken of the upper surface of hot rolled microalloyed steel skelp immediately following laminar cooling. In addition to validation of the skelp temperature and skelp cooling patterns, local temperature minimums were observed in the infrared images. Post processing of these images was undertaken to quantify both the spatial distribution and frequency of these temperature minimums. The measured transverse spacing of the temperature minimums correlates with the roughing mill descaler nozzle spacing. The genesis of the observed temperature minimums and, ultimately, their correlation with descaler functionality, and potential usage as an online descaler assessment tool, is postulated.
\end{abstract}

\section{Introduction}

Microalloyed steel skelp is produced using thermomechanical controlled processing (TMCP) and includes high temperature homogenization followed by rough and finish rolling of the steel. Temperatures incurred during TMCP range from a value of $\approx 1200^{\circ} \mathrm{C}$ in the homogenization furnace, from 1200 to $1100^{\circ} \mathrm{C}$ during rough rolling and from 900 to $800^{\circ} \mathrm{C}$ during finish rolling. After exiting the finishing mill, the steel skelp enters the laminar cooling system in which the steel is cooled to $\approx 500$ to $600^{\circ} \mathrm{C}$. Following, laminar cooling, the steel is coiled and allowed to cool to room temperature. Due to the high temperatures (and time) to which the steel is exposed, particularly in the homogenization furnace, an adherent oxide layer [1] may form and grow on the steel surface. To remove the oxide layer, high pressure water descalers are used before rough rolling and prior to finish rolling. The presence of a oxide scale on a steel skelp is important because of its potential impact on subsequent processing of the steel [2-4].

The functionality (i.e., ability to remove the oxide from the steel surface) of the descalers is difficult to assess in real time. Post processing analysis of a TMCP coil (typically 20 tonnes) would be required to accurately gauge the effectiveness of the descaler. This type of post processing analysis would be both time consuming and expensive. Thus, a mechanism/system for online assessment of descaler functionality would be beneficial. This paper details the potential usage of infrared video imaging to assess descaler functionality without the need for post TMCP processing coil assessment.

Pyrometers are used to measure skelp temperature throughout the TMCP process including at the exit of the laminar cooling system and before the coiling system. At this specific stage in the process, an infrared video imaging system was employed. The temperature information obtained from the infrared video camera was primarily to assess skelp temperature and provide verification for finite element thermal modelling of the skelp as it transits the laminar cooling system [7]. However, additional information obtained from the infrared thermal images (i.e., the presence of apparent cold spots) was used to assess descaler functionality.

\section{Oxide Scale on a Hot Rolled Steel Surface}

The mechanisms for oxide formation and growth on a steel surface are well known and have been researched extensively 1] - though primarily on experimental sized samples. The morphology of the oxide scale on hot rolled steel is a product of many different factors including; homogenization temperature, finishing rolling temperature, coiling temperature, location along the length of the coiled strip, distance from the edge of the strip, and steel composition. Typically, the oxide scale generated during TMCP consists of three distinct layers - a lower layer of wüstite $(\approx \mathrm{FeO})$, a middle layer of magnetite $\left(\mathrm{Fe}_{3} \mathrm{O}_{4}\right)$ and finally a top surface layer of hematite $\left(\mathrm{Fe}_{2} \mathrm{O}_{3}\right)$ - each with a different prevalence depending upon the above mentioned factors. At temperatures below $570^{\circ} \mathrm{C}$, FeO becomes thermodynamically unstable, however, it may still exists during transit through the laminar cooling system due to the kinetics of decomposition.

The presence (and thickness) of a particular oxide phase at the steel surface before coiling is important due to its potential effect on emissivity. The effective emissivity of the steel oxide is influenced by many different factors including; oxide scale transparency [5], roughness, scale composition, temperature and scale thickness [6]. It is this potential difference in oxide emissivity which may be exploited, in conjunction with infrared imaging, to assess the functionality of a hot strip mill descaler.

Previous work by the authors' [8] measured infrared temperature profiles across a steel skelp just prior to the coiler. In addition to observing realistic base metal temperatures, cold spots (i.e., localized low temperature readings significantly cooler $\left(>30^{\circ} \mathrm{C}\right)$ than the surrounding steel) were also observed. Finite element (FE) thermal modelling of the skelp as it transits the laminar cooling system [7] was conducted to assess the validity of these cold spots. Thermal simulations included the effect of varying thicknesses $(0 \mu \mathrm{m}$ to $500 \mu \mathrm{m})$ of surface oxide films on the predicted temperature of the steel surface following laminar cooling. The predicted difference in surface temperature of the steel (prior to entering the coiler) with and without the presence of a surface oxide was $<10^{\circ} \mathrm{C}$. The model results indicate 
that the cold spots observed with the infrared video images cannot be attributed to the thermal presence of an oxide. This earlier work attributed the presence of the cold spots to a change in local emissivity. The change in emissivity was likely due to a combination of many factors including a change in the oxide surface composition. To elucidate the genesis of these cold spots, measurement of the spatial distribution of these cold spots from a series of infrared images was undertaken to establish their relationship with the descaler positioning used in the TMCP process analyzed.

\section{Infrared Video Imaging and Spatial Measurement of Cold Spots}

Infrared video measurements along the length of $9 \mathrm{~m}$ thick microalloyed TMCP steel skelp were made with a Mikron M7640 infrared video camera [7]. This camera features an 8-14 $\mu \mathrm{m}$ spectral detection band and a $640 \times 480$ focal plane array microbolometer. An emissivity of 0.94 was assumed [7] in the converting the video camera images to actual temperature. The vertical position of the camera above the skelp, in conjunction with the camera resolution resulted in a $1.9 \mathrm{~m}$ by $1.3 \mathrm{~m}$ image that encompasses two thirds $(2 / 3)$ of the skelp surface. Based on the physical location of the camera from the strip, and on the number of pixels in the detector, each pixel recorded by the camera corresponds to a surface area of $3 \mathrm{~mm} \times 3 \mathrm{~mm}$ (on a stationary strip). Fig. 1a (top) is the infrared temperature image obtained for $475 \mathrm{~A} 14$ (frame 75) at a distance of $85 \mathrm{~m}$ along the skelp length. The top of the image corresponds to the edge of the skelp and the centreline position is indicated by a dashed horizontal line. The tonal variations observed in this figure correspond to an apparent difference in temperature. The infrared image in Fig. 1a exhibits alternating horizontal lines which correspond to an apparent variation in local temperature. A magnified view of Figure 1a taken near the centreline is shown in Fig. 1b (bottom image). This image contains two well defined "cold" spots that are elongated along the length of the skelp in the rolling direction.

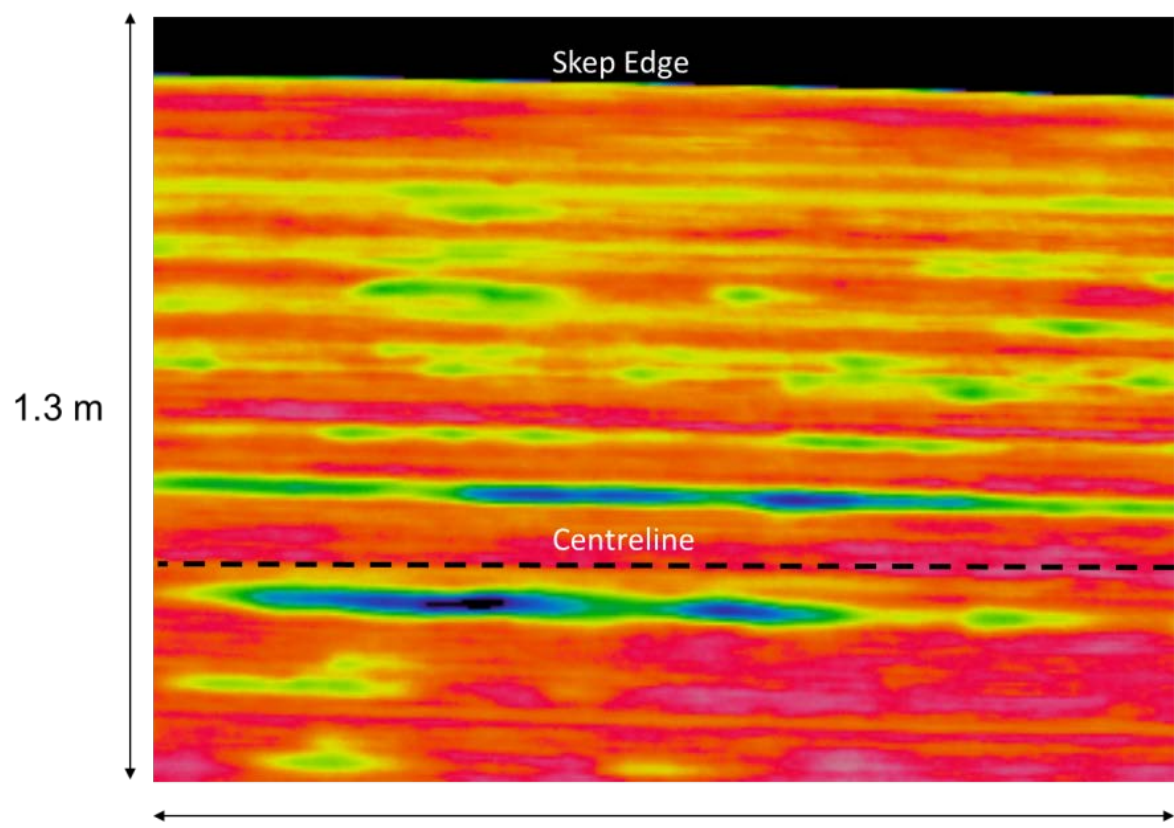

$1.9 \mathrm{~m}$

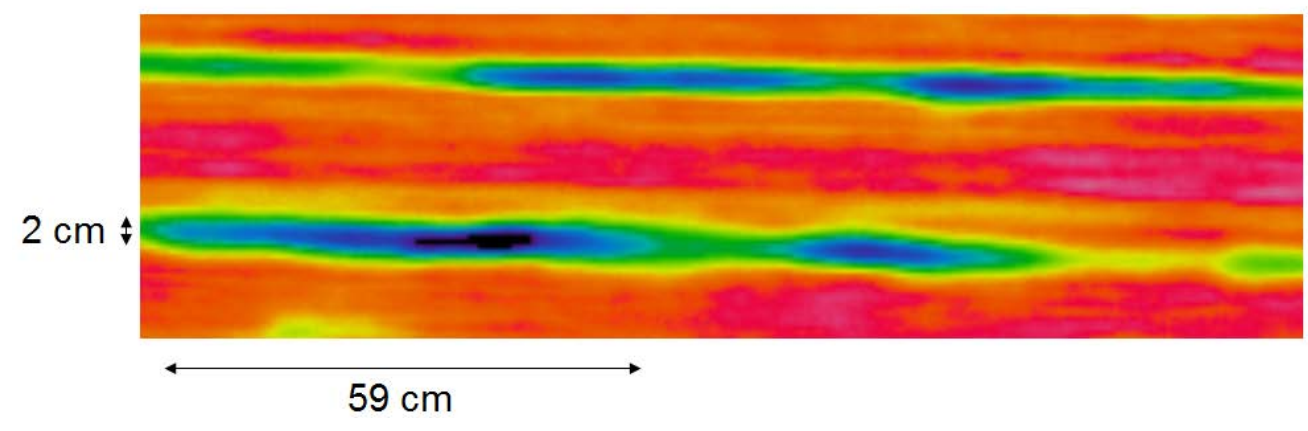

Fig. 1 Frame 75 of strip 475A14 : a) Infrared surface image and b) Magnified image near centreline. 
Fig. 2 graphs the temperature values measured across the width of $475 \mathrm{~A} 14$ (frame 75 ). The temperature traverse correspond to the dashed vertical line on the infrared image inset in the Fig. 2 . A position of $x=0.0 \mathrm{~m}$ in Fig. 2 corresponds to the skelp edge near the top of Fig. 1a. The centreline is at a position of $x=0.9 \mathrm{~m}$. Several temperature minimums (i.e., cold spots) of $30^{\circ} \mathrm{C}$ and $103^{\circ} \mathrm{C}$ are highlighted in the temperature profile shown in Fig. 2. Also included in this figure are vertical dashed lines which indicate the transverse position of each temperature minimum $\left(\geq 30^{\circ} \mathrm{C}\right)$ measured for this image. For example, the $103^{\circ} \mathrm{C}$ temperature valley corresponds to distance (from the top edge) of $0.774 \mathrm{~m}$. A temperature drop of $>30^{\circ} \mathrm{C}$ was used as it is unlikely that a temperature difference of this magnitude could arise solely from the laminar cooling system [7]. The spatial positioning of additional cold spots in the figure are also shown with dashed vertical lines.

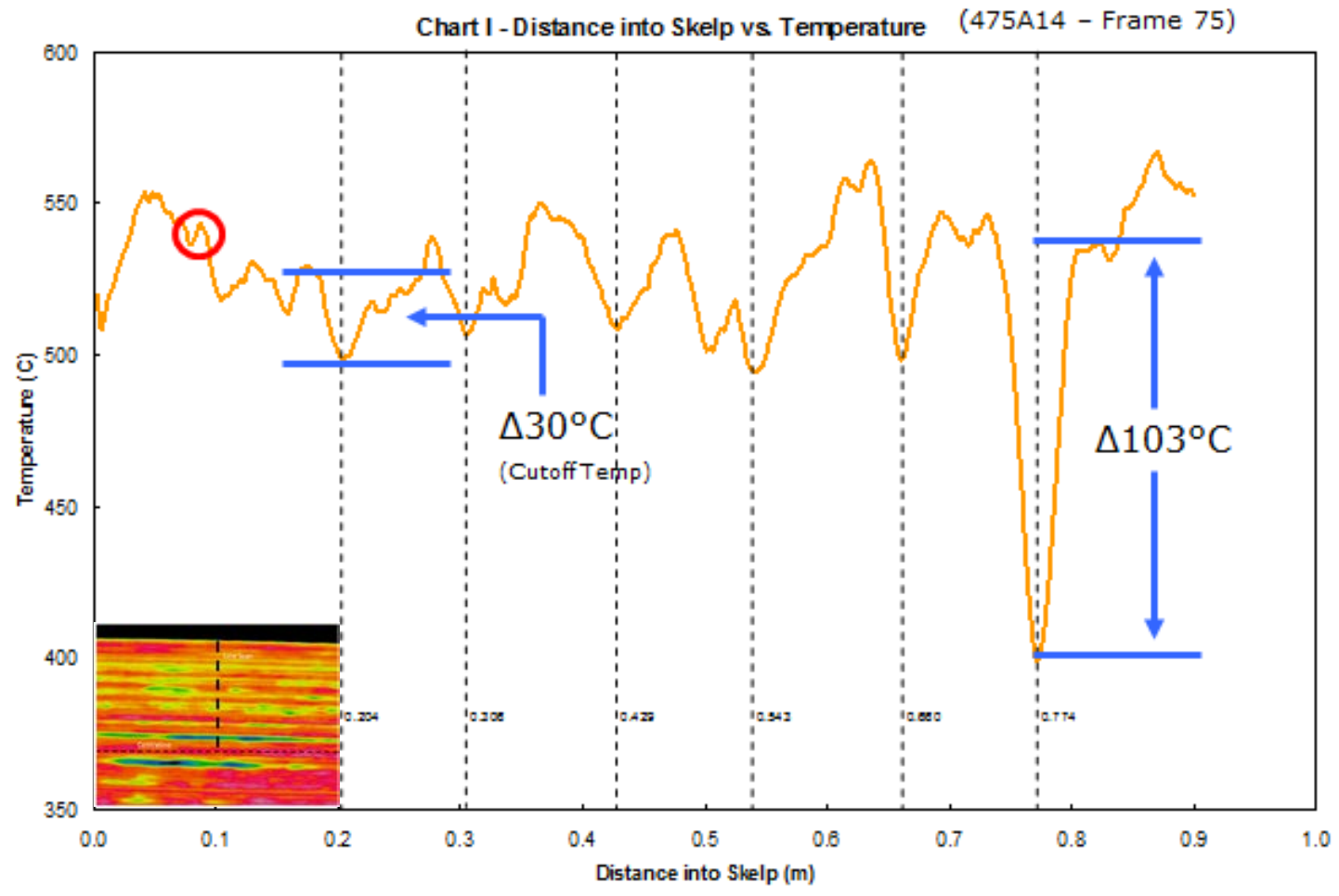

Fig. 2 Spatial characterization of cold spots from a transverse temperature profile from skelp 475A14.

\section{Spatial Distribution of Cold Spots}

This process of identifying (Fig. 2) the transverse spatial positioning of the temperature minimums $\left(\geq 30^{\circ} \mathrm{C}\right)$ was repeated on infrared video images taken from the TMCP processing of twelve (12) separate slabs. The slabs analyzed were from two heats (475 and 593) of X-70 steel and were TMCP processed in random order over a period of two days. As the number of infrared video frames for each slab was in excess of 100 , the analysis was simplified by selecting 10 video frames from each skelp to analyze. The spacing of the frames corresponds to a distance along the skelp of approximately 15 to 20 metres.

Fig. 3 shows the spatial positioning (i.e., transverse and longitudinal positions) of the cold spots measured for 475A14. The individual data points have error bars of $\pm 15 \mathrm{~mm}$. This error bar corresponds to the observed lateral motion of the skelp prior to entering the coiling system. Also included in this figure are horizontal coloured bands that approximate the localized clustering of the data at specific distances from the drive side edge. Each coloured band is 30 $\mathrm{mm}$ wide.

From Fig. 3, is apparent that the cold spots (clustered along the coloured bands) are located at repeatable transverse skelp positions along the length of the skelp. Double arrowed vertical lines - whose vertical length represents the roughing mill descaler nozzle separation distance - have been added to Fig. 3 on the left hand side of the graph. These lines closely approximate the spacing of the coloured bands and indicate that the cold spot spacing is closely aligned with the roughing mill descaler nozzle spacing. 


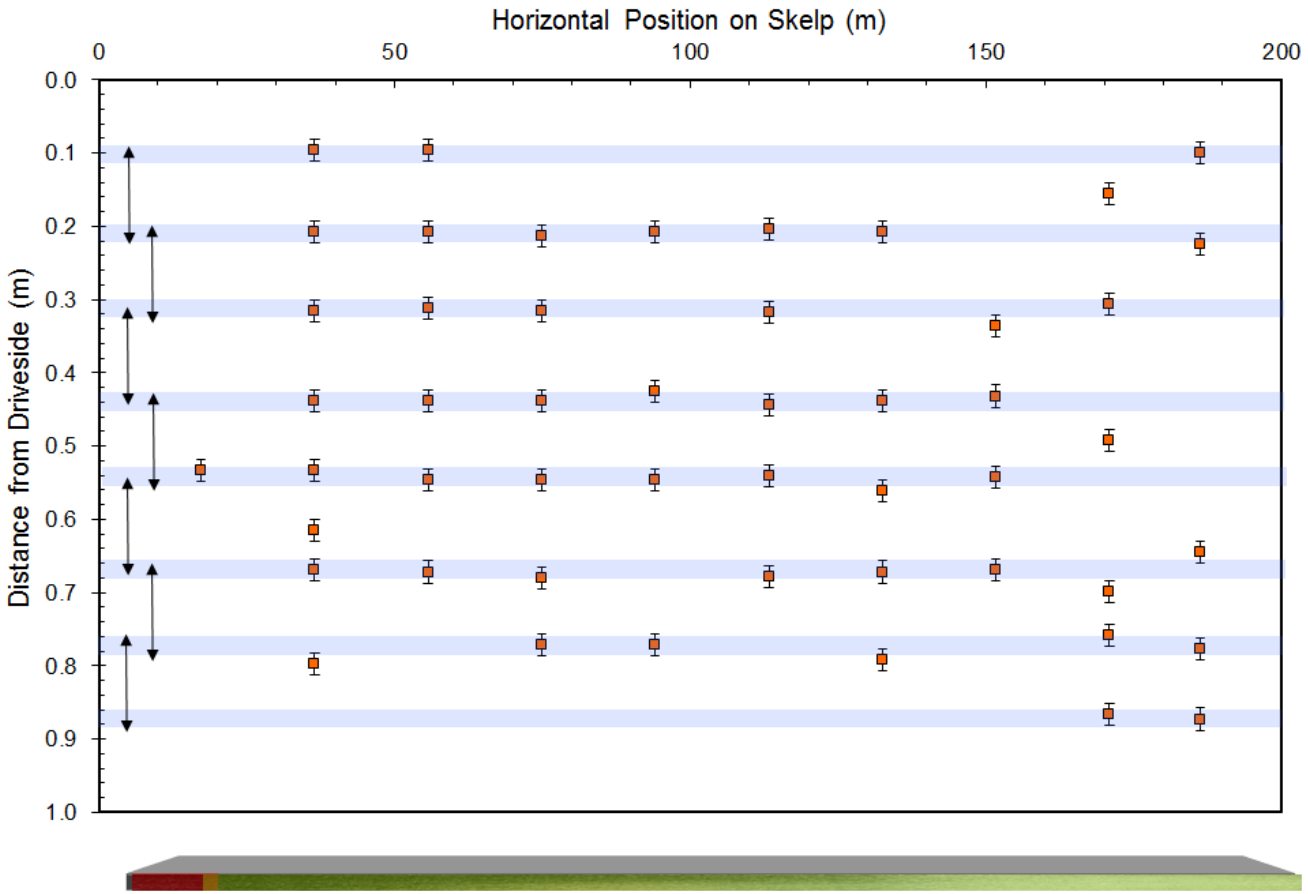

Fig. 3 Spatial positioning of cold spots for 475A14

The measured spatial position for all twelve coils is shown in Fig. 4. Similar to Fig. 3, the spatial positioning of the cold spots are grouped into bands though a larger variation of cold spot positioning is observed at transverse positions greater than $0.68 \mathrm{~m}$. The percentage of cold spots observed at each transverse position for each rolling period (Thursday PM, Friday AM and Friday PM) is shown in Fig. 5. The band numbers are labelled sequentially with B1 near the top edge and B8 near the centerline. The greatest percentages of cold spots are concentrated in Bands 2-5 and are relatively independent of the rolling date. This consistency across the time period analyzed suggests that the cold spots observed are not connected with the variables associated with an individual slab (e.g., composition, time in homogenization furnace, etc.)

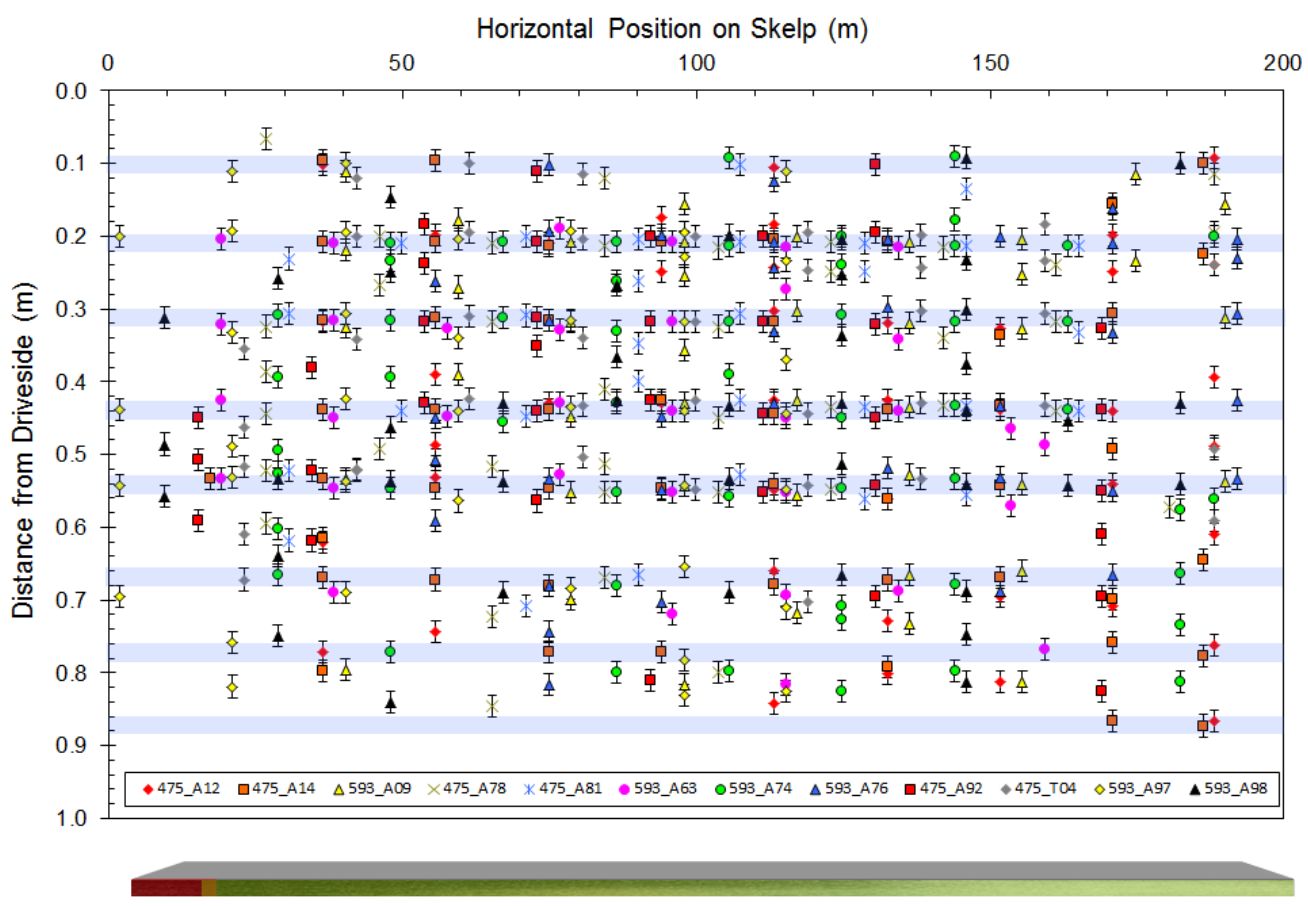

Fig. 4 Spatial positioning of cold spots for all slabs. 


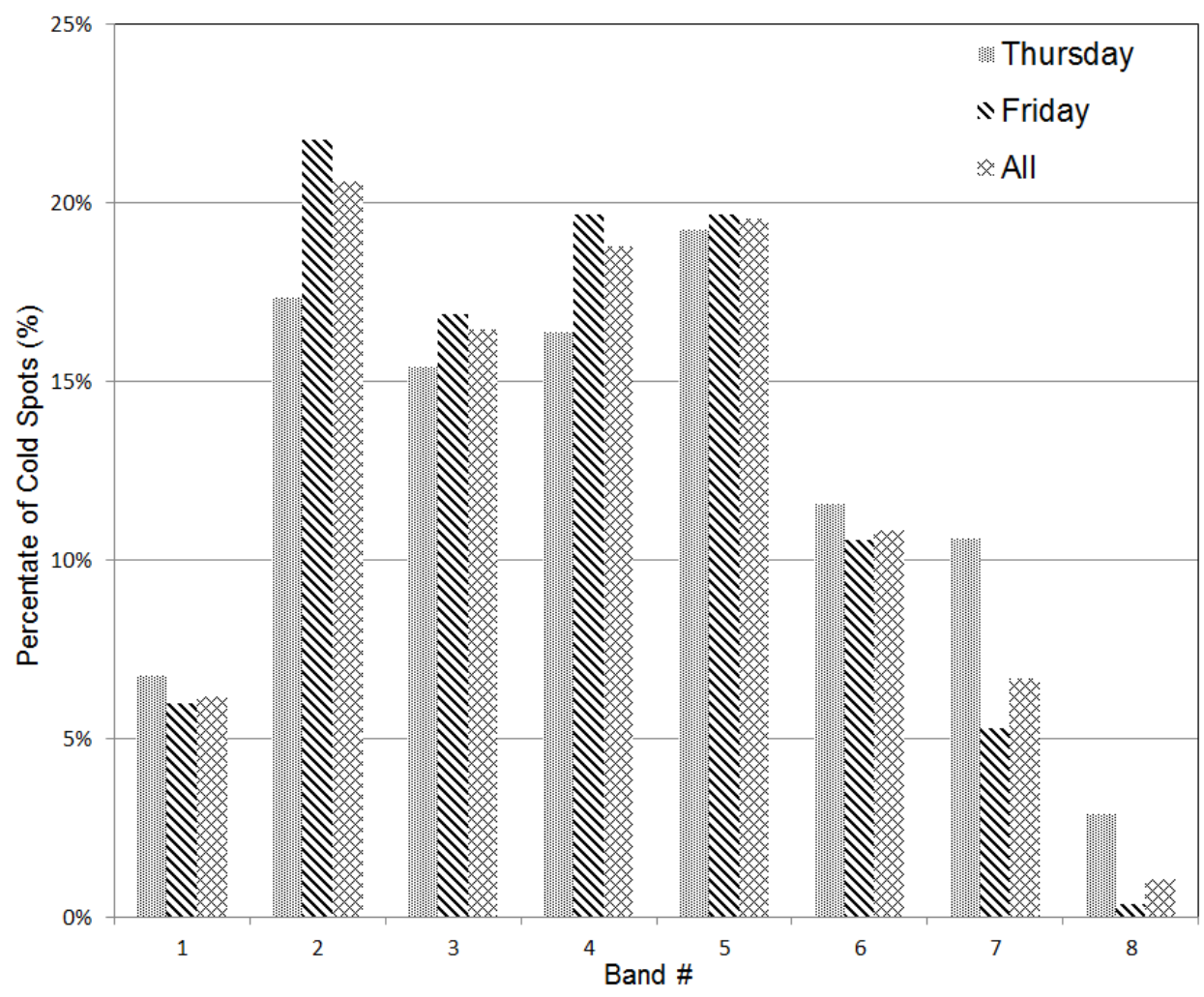

Fig. 5 Frequency distribution of the number of cold spots for each band.

The spatial distribution measurements were repeated using a criteria of $>50^{\circ} \mathrm{C}$ for all the rolled slabs. The spatial positioning of cold spots along the length of the skelp and the frequency distribution are shown in Fig. 6a and Fig. 6b, respectively. Similar to Fig. 4, a high percentage of the cold spots are observed to occupy Band 2 to 5 with Band 2 exhibiting the highest number of $>50^{\circ} \mathrm{C}$ cold spots (Fig. 6b)
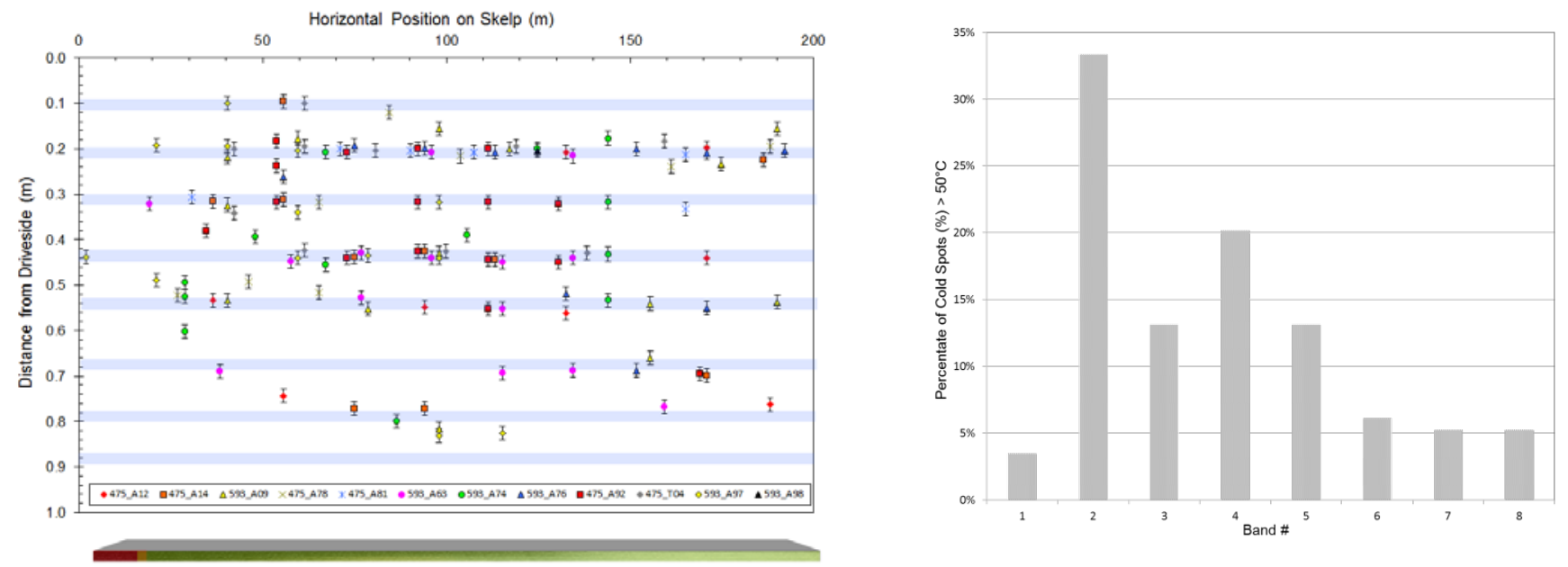

Fig. 6 a) Spatial distribution and b) Frequency distribution for cold spots $>50^{\circ} \mathrm{C}$.

\section{Discussion}

The data presented in the previous section suggests that the occurrence and frequency of cold spots is possibly connected with the roughing mill descaler nozzle spacing. It is not known whether the band (B1-B8) location is associated with a position directly under each descaler or is positioned midpoint between the descaler nozzles as shown in Fig. 7a. In addition, it is observed that the cold spots can be elongated in the rolling direction which suggests that the surface characteristic associated with the cold spot is elongated during the rolling process (Fig. 1b). 
The following scenario is hypothesized for the formation and presence of the cold spots:

1] Due to both a sufficiently strong adherence of the oxide (i.e., FeO) to the steel substrate and a potentially non-optimal functioning of the descaler nozzles, the descaler may not entirely remove the original oxide layers (Fig. 7b). A portion of the original scale (i.e. the FeO) may remain on the surface (Fig. 7c).

2] FeO can exhibit relatively high ductility at the rough rolling temperature [9] and the portion remaining after descaling (Fig. 7c) is deformed and elongated during the rough rolling process. This elongation is observed in Fig. $1 \mathrm{~b}$.

3] The presence this slightly thicker oxide scale retained through the TMCP process may result in a difference in the effective emissivity and would appear as a cold spot in the infrared images. As discussed earlier there are many possible factors that may influence this change in effective emissivity including the relative thickness and type of the oxide layers, the surface roughness and potentially the surface temperature variation imposed during laminar cooling which may affect the type of oxide.

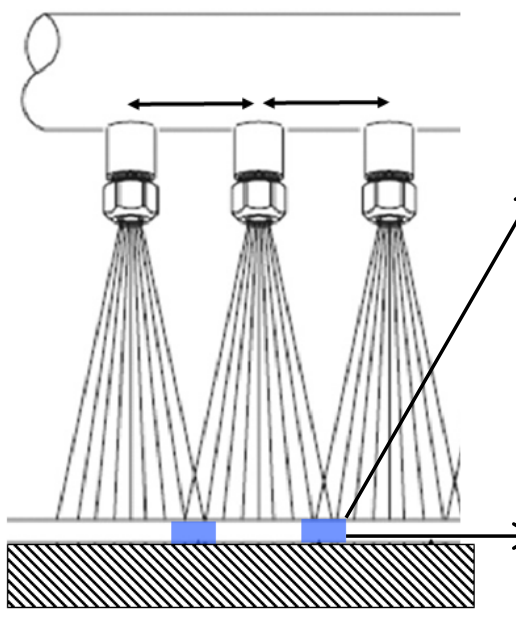

(a)

\section{Hematite $-\mathrm{Fe}_{2} \mathrm{O}_{3}$ Magnetite $-\mathrm{Fe}_{3} \mathrm{O}_{4}$}

Wustite - FeO

Wustite - FeO

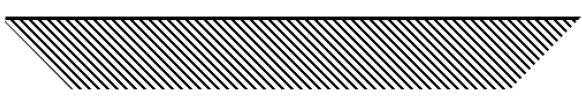

(c)

Fig. 7 a) Possible cold spot band location relative to the descaler nozzle spacing b) Original oxide layering and c) Post descaler oxide layer of FeO remaining on the surface

Fig. 8 graphs the predicted surface temperature as a function time (i.e., position) in the laminar cooling system without and with the presence of a $100 \mu \mathrm{m}$ layer of oxide. The minimum temperature the surface reaches (for the $100 \mu \mathrm{m}$ oxide layer) is $370^{\circ} \mathrm{C}$. This temperature is significantly below the thermodynamic stability of $\mathrm{FeO}\left(570^{\circ} \mathrm{C}\right)$. Conversely, the oxide free simulation $(0 \mu \mathrm{m})$ only exhibits a minimum surface temperature of $\approx 520^{\circ} \mathrm{C}$. The difference in the predicted cooling temperature may be sufficient to alter the oxide layer phases that are present [11] which in turn would affect the effective emissivity.

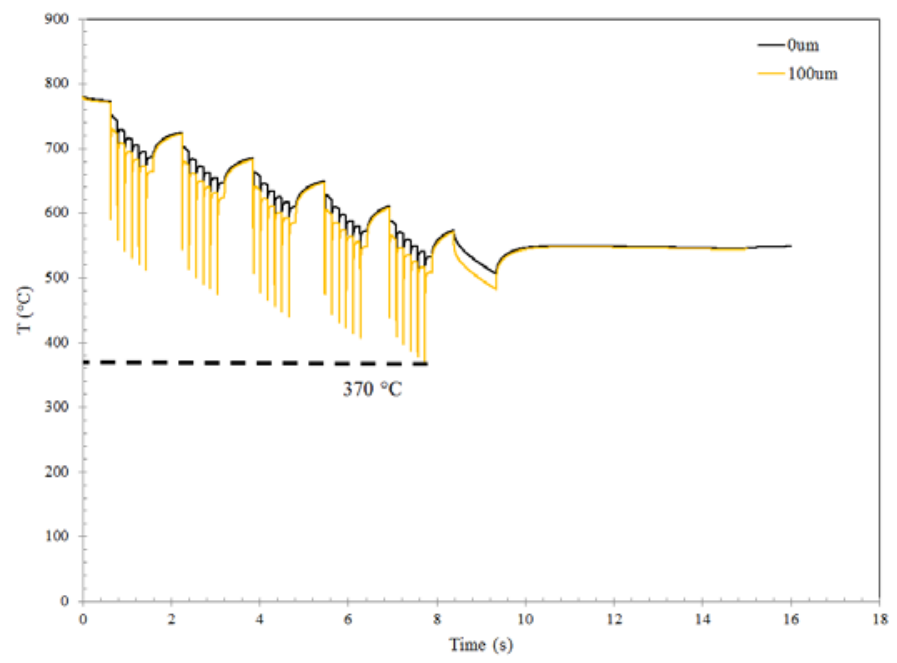

Fig. 8 Finite element simulation of laminar cooling no surface oxide $(0 \mu \mathrm{m})$ and with a $100 \mu \mathrm{m}$ thick oxide. 
For the 8-14 $\mu \mathrm{m}$ spectral detection band used in the infrared video camera the change in emissivity that would account for a $30^{\circ} \mathrm{C}$ temperature drop at the cold spots can be approximated [12] by:

$$
\frac{\Delta T}{T}=\frac{\lambda}{5 \cdot \lambda_{\max }} \cdot \frac{\Delta \varepsilon}{\varepsilon}
$$

where $\Delta T$ is the change in calculated temperature for a given change in emissivity $(\Delta \varepsilon)$. Assuming the peak wavelength $\lambda_{\max }$ is $3.32 \mu \mathrm{m}\left(\right.$ at $600^{\circ} \mathrm{C}$ ) and the effective wavelength used for the measurement $\lambda$ is $11 \mu \mathrm{m}$, then for a $\Delta T=--30^{\circ} \mathrm{C}$ the value of $\Delta \varepsilon=-0.071$. For the system being analyzed this would correspond to an emissivity of $\approx 0.87$. Data on the emissivity of different oxide phases at the skelp temperature following laminar cooling and before the coiler are not available in the literature. However, Sprague et al. [13], reported that the spectral emissivity of hematite $\left(\mathrm{Fe}_{2} \mathrm{O}_{3}\right)$ can range from 0.76 to 0.97 in the wavelength range of $8-14 \mu \mathrm{m}$ at room temperature. Del Campo et al. [5] measured an emissivity's in the range from 0.72 to 0.90 (for a wavelength $8-12 \mu \mathrm{m}$ ) at $480^{\circ} \mathrm{C}$ for oxidizing steel.

\section{Conclusions}

1] Cold spots observed during infrared imaging of a steel skelp - following laminar cooling and before coiling - exhibit spatial positioning that are comparable to the roughing mill descaler nozzle spacing.

2] The frequency of observed cold spots varied across the skelp width which may be indicative of differences in descaler nozzle functionality across the width

3] Finite element thermal analysis indicates that cold spot temperature measurements in excess of $30^{\circ} \mathrm{C}$ cannot be attributed to an actual temperature difference and are most likely the results of a localized change in surface emissivity.

4] This work indicates the potential for using infrared video analysis as a means assessing individual descaler nozzle functionality via the spatial positioning and frequency of cold spots observed on the surface.

\section{Acknowledgements}

The authors would like to thank EVRAZ N.A. Inc. for allowing access to their plant. We would also like to thank NSERC EVRAZ N.A. Inc. and TCPL for financial support and L. Collins of EVRAZ N.A. Inc. for facilitating this work.

\section{References}

[1] Chen, R. Y., and W. Y D Yuen. Oxide-Scale Structures Formed on Commercial Hot-Rolled Steel Skelp and Their Formation Mechanisms. Oxidation of Metals 56.1/2 (2001): 89-118.

[2] Gines, M. J L, G. J. Benitez, T. Perez, E. Merli, and W. Egli. Study of the Picklability of 1.8mm Hot-rolled Steel Strip in Hydrochloric Acid. Latin American Applied Research 32 (2002): 281-88.

[3] M. Krzyzanowski, , J. H. Beynon and D.C. Farrugia. Oxide scale behaviour in high temperature metal processing. Wiley-VCH, 2010.

[4] H. Okada. Deformation Behavior of Oxide Scale in Hot Strip Rolling. Nippon Tech. Report. No. 111, 2016

[5] Del Campo, Leire, Raul B. Perez-Saez, and Manuel J. Tello. "Iron Oxidation Kinetics Study by Using Infrared Spectral Emissivity Measurements below 570 C." Corrosion Science 50 (2007): 194-99.

[6] Zhorov, G. A., and K. A. Yagunov. "Effect of Thickness of Oxide Film on the Emissivity and Reflectivity of HeatResistant Metals and Alloys." All-Union Institute of Aviation Materials 34.1 (1978): 34-39.

[7] J.B. Wiskel, H. Deng, C. Jefferies and H. Henein, "Infrared Thermography of a TMCP Microalloyed Steel Skelp at the Upcoiler and Its Application in Quantifying the Laminar Jet/Skelp Interaction", Ironmaking and Steelmaking, Vol. 38,1, , pp. 35-44, 2011.

[8] J. B. Wiskel, J. Prescott and H. Henein." Finite Element Thermal Analysis of Surface Cold Spots Observed during Infrared Video Imaging of a Moving Hot Steel Strip", QIRT 2014.

[9] Y. Hidaka, T. Anraku and N. Otsuka, "Deformation of Iron Oxides upon Tensile Tests at $600-1250^{\circ} \mathrm{C}, \mathrm{Oxid}$ Met., Vol. 59 (1-2), pp. 97-113, 2003.

[10] T. Kizu, Y. Nagataki, T. Inazumi and Y. Hosoya, "Effects of Chemical Composition and Oxidation Temperature on the Adhesion of Scale in Plain Carbon Steels", ISIJ Int., Vol. 41 (12), pp. 1494-1501, 2001.

[11] S. Liu, D. Tang, H. Wu and L. Wang, "Oxide Scales Characterization of Microalloyed Steel at High Temperature", J. Mat. Proc. Tech., 213, 2013, pp. 1068-1075.

[12] R.F. Leftwich, Theory and Practice of Radiation Thermometry, eds. D.P. DeWitt and G. Nutter, John Wiley and Sons, New York, 1988, p502.

[13] A.L. Sprague, T.L. Roush, R.T. Downs and K. Righter, Response to Comment on Comparison of Laboratory Emission Spectra with Mercury Telescopic Data", ICARUS, 143, pp. 409-411, 2000. 